\title{
Sliding Mode Control Based on RBF Neural Network for Parallel Machine Tool
}

\author{
Jiye Yang ${ }^{1}$, Yongfeng $\mathrm{Cui}^{2, *}$ and Miaochao $\mathrm{Chen}^{3}$
}

\author{
${ }^{I}$ School of Basic Education, Jiangsu Food \& Pharmaceutical Science College, Huaian, 223000, P. R. China; ${ }^{2}$ School of \\ Computer Science and Technology, Zhoukou Normal University, Henan, 466001, P. R. China; ${ }^{3}$ Department of Mathe- \\ matics, Chaohu University, Hefei, 238000, P. R. China
}

\begin{abstract}
The hydraulic control system, an important composition of parallel machine tool, is a high order, nonlinear, parameter uncertain system, which seriously affects the dynamic performance of a machine tool, so it is very difficult to gain good performance with traditional control methods. The sliding mode control method based on RBF neural network is proposed in this paper. From the simulation results we can obtain that the proposed method is better than the traditional sliding model control method. Moreover, the result validates the proposed method of Hydraulic system for parallel machine tool and also provides the theoretical and experimental basis.
\end{abstract}

Keywords: Hydraulic servo system, parallel machine tool, RBF neural network, SMC

\section{INTRODUCTION}

Research about the parallel mechanism can be traced back to the 19th century. Gough produced a tire test device by using the parallel mechanism in 1949. The British engineer, Stewart, has published a paper entitled "a platform with six degrees of freedom" [1]. The above mentioned Stewart platform consisted of the upper and lower platforms and six struts. These six struts are cylinders with pistons inside to afford them independent movement The struts are coupled by the upper and lower platform and ball joints and Hooke hinge. The lower platform is fixed and the upper platform can move at six degrees of freedom. [2].

Parallel Machine Tool, which is based on the principle of the parallel mechanism in Stewart's platform (Fig. 1), is derived from the combination of parallel robot mechanism and machine tools. It has high stiffness, high bearing capacity, high accuracy of positioning and smaller work space, compared with the traditional serial mechanism, and it can reduce the static error and dynamic error of machine tools and robots [3]. The flow-pressure and oil leakage of the servo system causes it to have many uncertainties and highly nonlinear characteristics. Therefore, it is difficult for the traditional design methods of control system to meet the control requirements of the parallel robot with six degrees of freedom [4].

In recent years, experts conducted a theoretical analysis and experiments to research parallel robots with six degrees of freedom on robust optimal control [5], two degrees of freedom PID control, adaptive control before the disturbance force feed forward compensation control and so forth [6]. They obtained some guidance results, but the control effect is still difficult to meet the actual requirements.

Sliding mode control [7-9] is robust with respect to system uncertainties by the use of switching control. But it has disadvantage of chattering $[10,11]$. In order to reduce the chattering of the servo system, a sliding mode control algorithm with RBF neural network $[12,13]$ is proposed in this paper, and the chattering can be reduced effectively.

\section{SYSTEM COMPONENTS}

The parallel robot's control system can be divided into five parts: the control computer functions, electrohydraulic servo control unit, actuator unit, hydraulic system

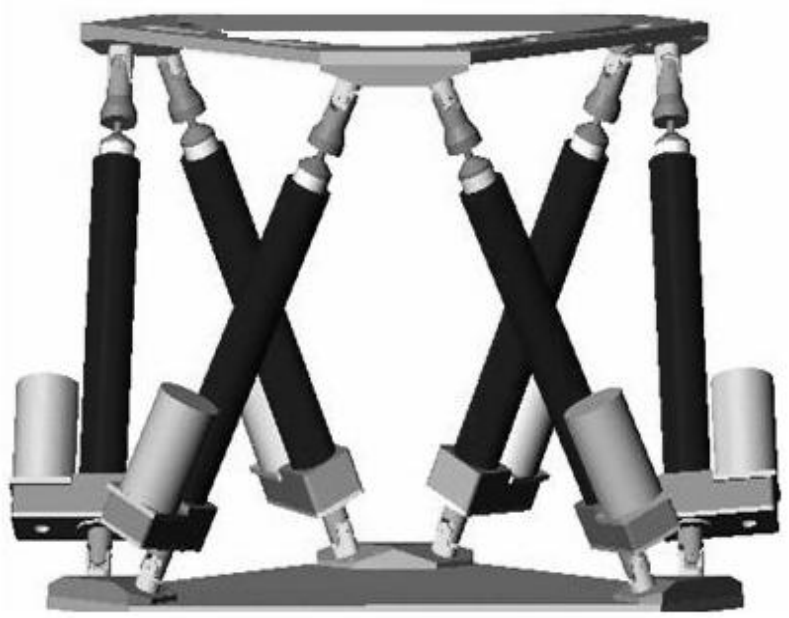

Fig. (1). Stewart platform. 


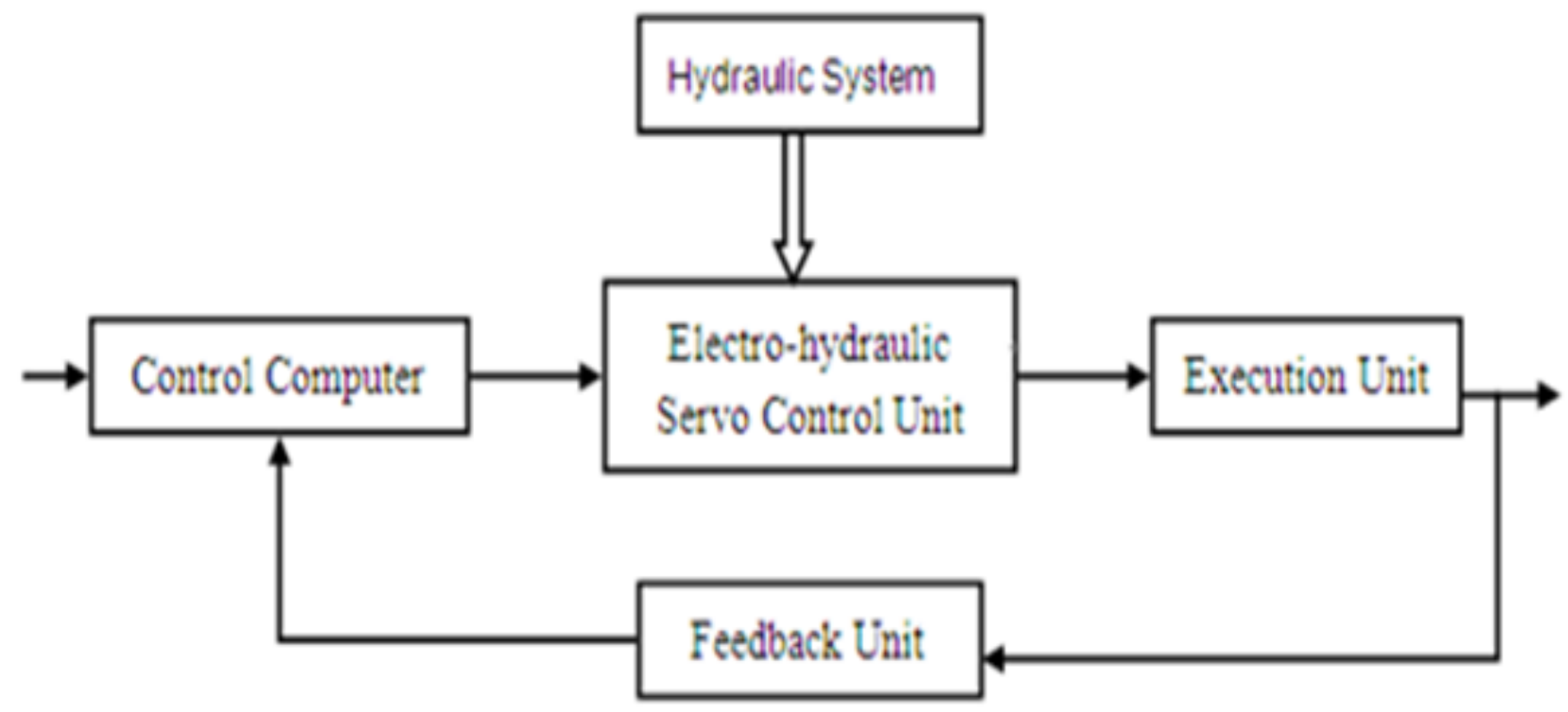

Fig. (2). The figure of components.

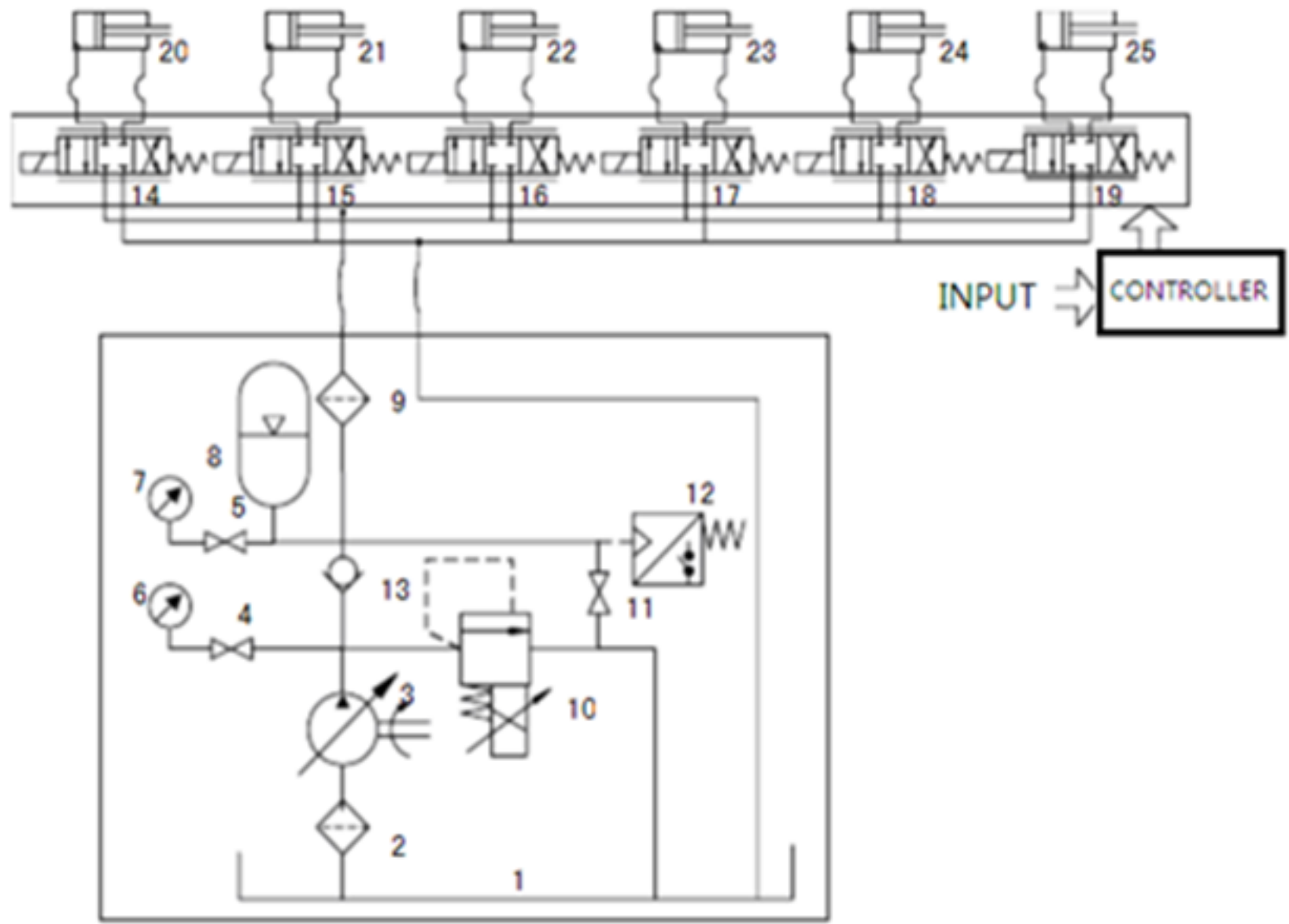

Fig. (3). Hydraulic system of the parallel robot with 6-DOF.

and the feedback unit. The schematic of components are shown in Fig. (2).

The parallel robot with 6-DOF is driven by using hydraulic force, the six hydraulic cylinders control the movement of the platform, the movable platform (translational and rotational) can move in the six degrees of freedom, the entire hydraulic system consists of hydraulic stations, servo valve, hydraulic cylinder hydraulic servo controllers and components (Fig. 3) [14]. 


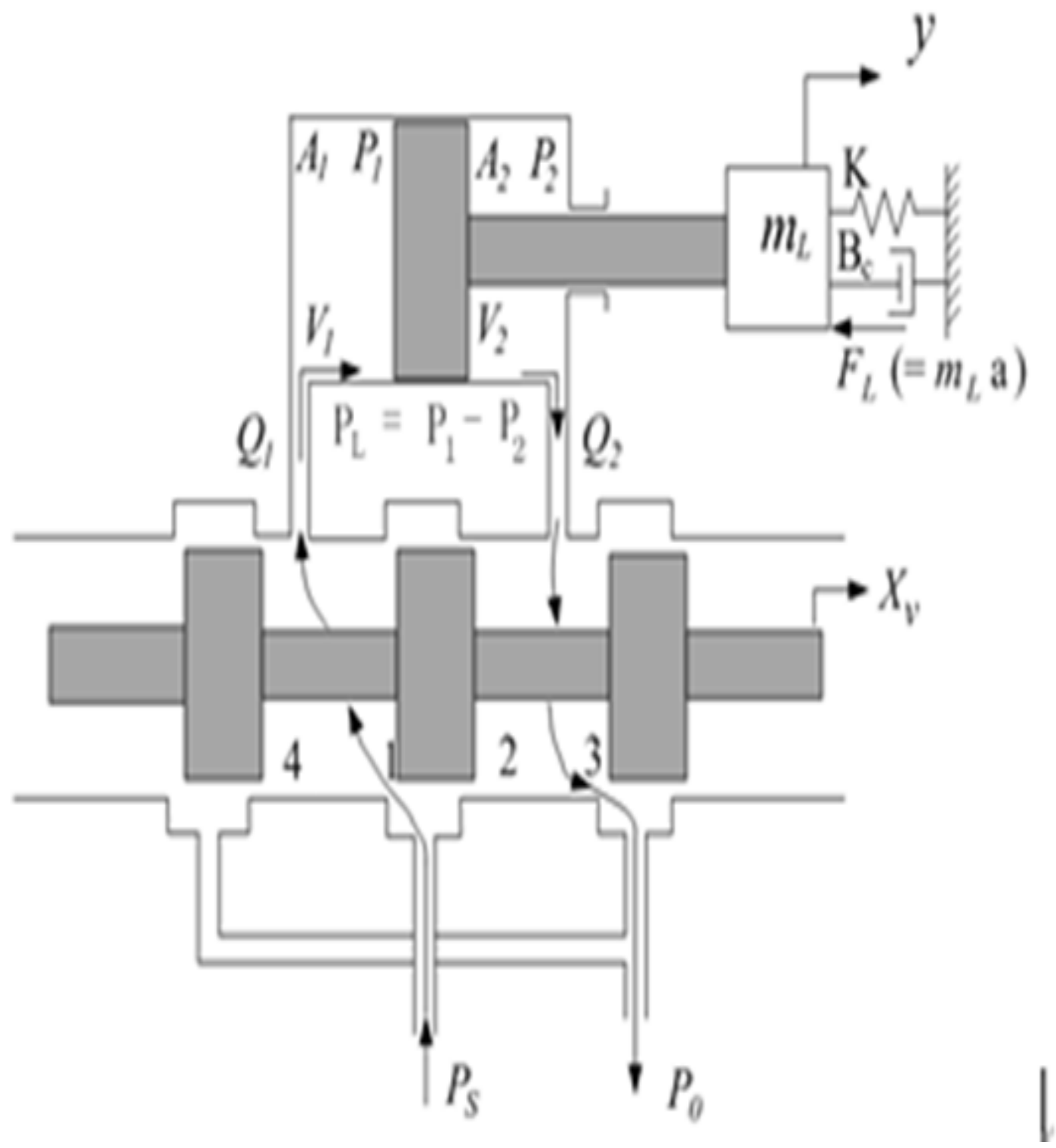

Fig. (4). Schematic diagram for valve controlled asymmetrical cylinder.

\section{MATHEMATICAL MODEL}

The Hydraulic cylinder servo system of Stewart platform consists of servo valve, hydraulic cylinder, load and so forth, The structure of the valve controlled asymmetrical cylinder is shown in Fig. (4).

Assumption: Four orifice port of the servo valve are matched and symmetrical. The supply pressure PS is constant and the return oil pressure $P_{0}$ is zero.

Based on the above assumptions, the dynamic equation for the valve-controlled valve controlled asymmetrical cylinder can be obtained.

The flow equation of the hydraulic cylinder is given as:

$$
=K_{q} x_{v}-K_{c} p_{L}
$$

2) Continuity equation is given as:
$Q_{L}=A_{1} \frac{d y}{d t}+\frac{V_{t}}{2\left(1+n^{2}\right) \beta_{e}} \frac{d p_{L}}{d t}+C_{t c} p_{L}+C_{t c 1} p_{s}$

3) The force balance equation of hydraulic cylinder is given as:

$=m_{L} \frac{d^{2} y}{d t^{2}}+B_{c} \frac{d y}{d t}+K y+F_{L}$

With Laplace transformation for (1), (2), (3),

$\left\{\begin{array}{l}Q_{I}=K_{e} X_{v}-K_{c} p_{I} \\ Q_{I}=A_{I} s Y+\frac{V_{f}}{2\left(1+n^{2}\right) \beta_{e}} s p_{I}+C_{f c} p_{I}+C_{f c} p_{s} \\ A_{I} p_{I}=\left(m_{I} s^{2}+B_{c} s+K\right) Y+F_{I}\end{array}\right.$ 


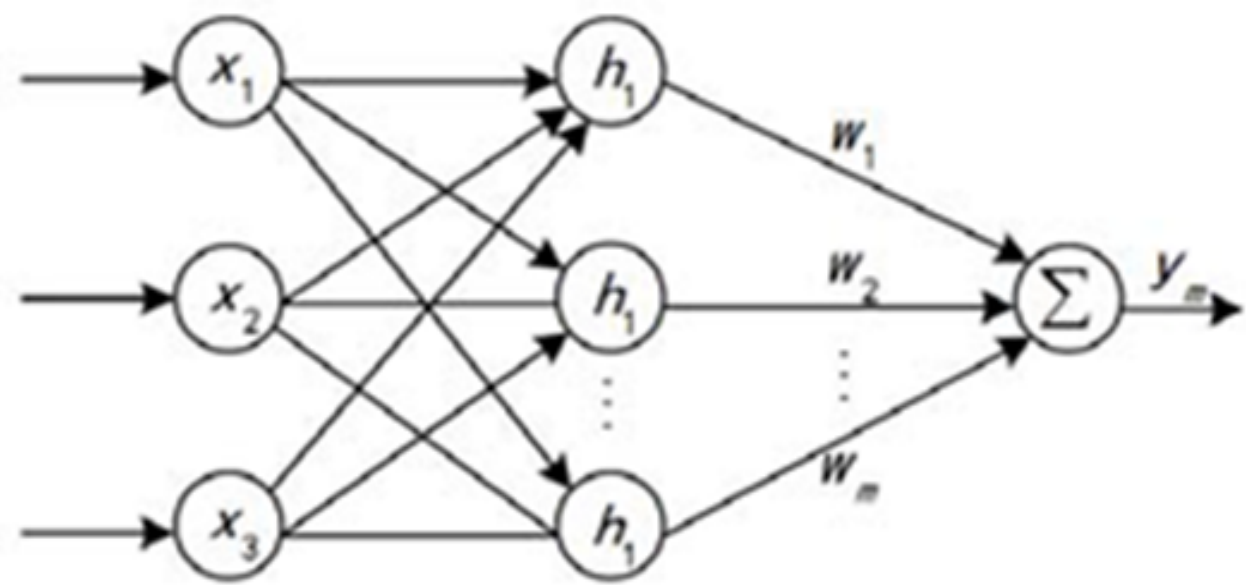

Fig. (5). The scheme diagram of RBF Neural Network.

$$
\frac{Y}{X_{v}}=\frac{\frac{K_{q}}{A_{1}}}{s\left(\frac{s^{2}}{\omega_{k}^{2}}+\frac{2 \xi_{k}}{\omega_{k}} s+1\right)}
$$

Where

$$
\begin{aligned}
& \omega_{h}=\sqrt{\frac{2\left(1+n^{2}\right) \beta_{e} A_{1}^{2}}{m_{L} V_{t}}} \\
& +\frac{K_{c}+C_{t c}}{A_{1}} \sqrt{\frac{\left(1+n^{2}\right) \beta_{e} m_{I t}}{2 V_{t}}}
\end{aligned}
$$

The transfer function of the valve-controlled valve controlled asymmetrical cylinder can be obtained [3].

\section{NEURAL NETWORK SLDING MODE CONTROL BASED ON RBF}

The Radial Basis Function (RBF) is a three layered feed forward network with a single hidden layer (Fig. 5), and it is a kind of local approximation of the neural network. For the practical application, the object features and models are changed frequently but changing slowly. Setting and well optimized SMC parameters may no longer have a very good control effect after a period of time [10, 14-16] .The neural network intelligence SMC controller can identify the model and features of the controlled object through identifier [17]. There are many functional forms of RBF neural network, Gauss function was selected in this article as the hidden layer node function according to its unique advantages. The network input is given as

$$
X=\left[\begin{array}{llll}
x_{1} & x_{2} & \cdots & x_{n}
\end{array}\right]^{T},
$$

the hidden layer of network output is given as

$$
H=\left[\begin{array}{llll}
h_{1} & h_{2} & \cdots & h_{m}
\end{array}\right]^{T},
$$

the gauss function is given as $h_{j}$.

$$
\begin{gathered}
h_{j}=\exp \left(-\frac{\left\|X-C_{j}\right\|^{2}}{2 b_{i}^{j}}\right)^{2}(j=1,2, \cdots, m) \\
\text { Where } C_{j}=\left[\begin{array}{llll}
c_{j 1} & c_{j 2} & \cdots & c_{j n}
\end{array}\right]^{T}, \\
b_{j}=\left[\begin{array}{llll}
b_{j 1} & b_{j 2} & \cdots & b_{j n}
\end{array}\right]^{T},
\end{gathered}
$$

and the number of hidden layer is given as $\mathrm{m}$.

$W=\left[w_{1} w_{2} \cdots w_{n}\right]^{T}$

The network output is given as:

$u_{n}(k)=w_{1} h_{1}+w_{2} h_{2}+\cdots+w_{m} h_{m}$

The RBF network output is given as:

$x_{n}(1)=s(k), x_{n}(2)=s(k)-s(k-1)$

Aimed at the output of the RBF network, the sliding mode controller is designed as following, namely

$u=\sum_{j=1}^{m} w_{j} \exp \left(-\frac{\left\|s-c_{j}\right\|^{2}}{b_{j}}\right)$

The BRF network's weights adjustment index is given as:

$E=s(t) \dot{s}(t)$

Namely

$=-\eta \frac{\partial s(t) \dot{s}(t)}{\partial u(t)} \frac{\partial u(t)}{\partial w_{j}(t)}(\eta>0)$

Because of 


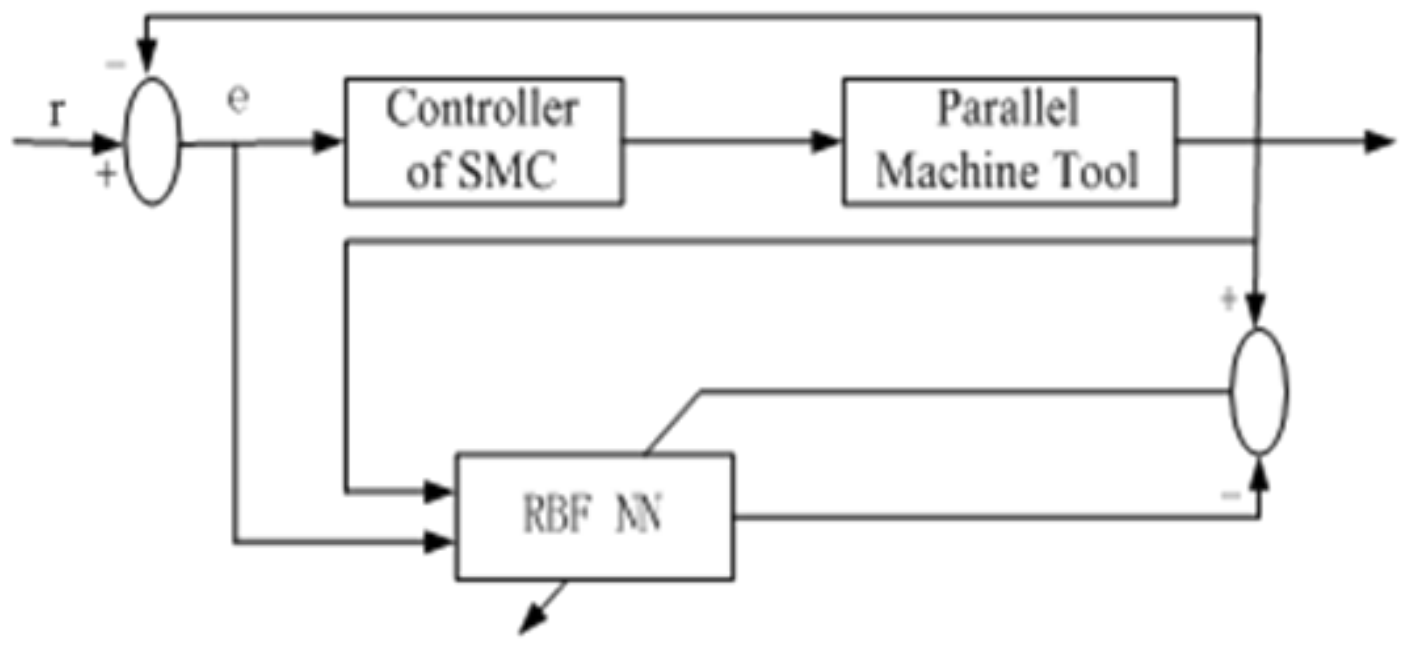

Fig. (6). The structure of sliding mode controller with RBF neural sliding mode controller.

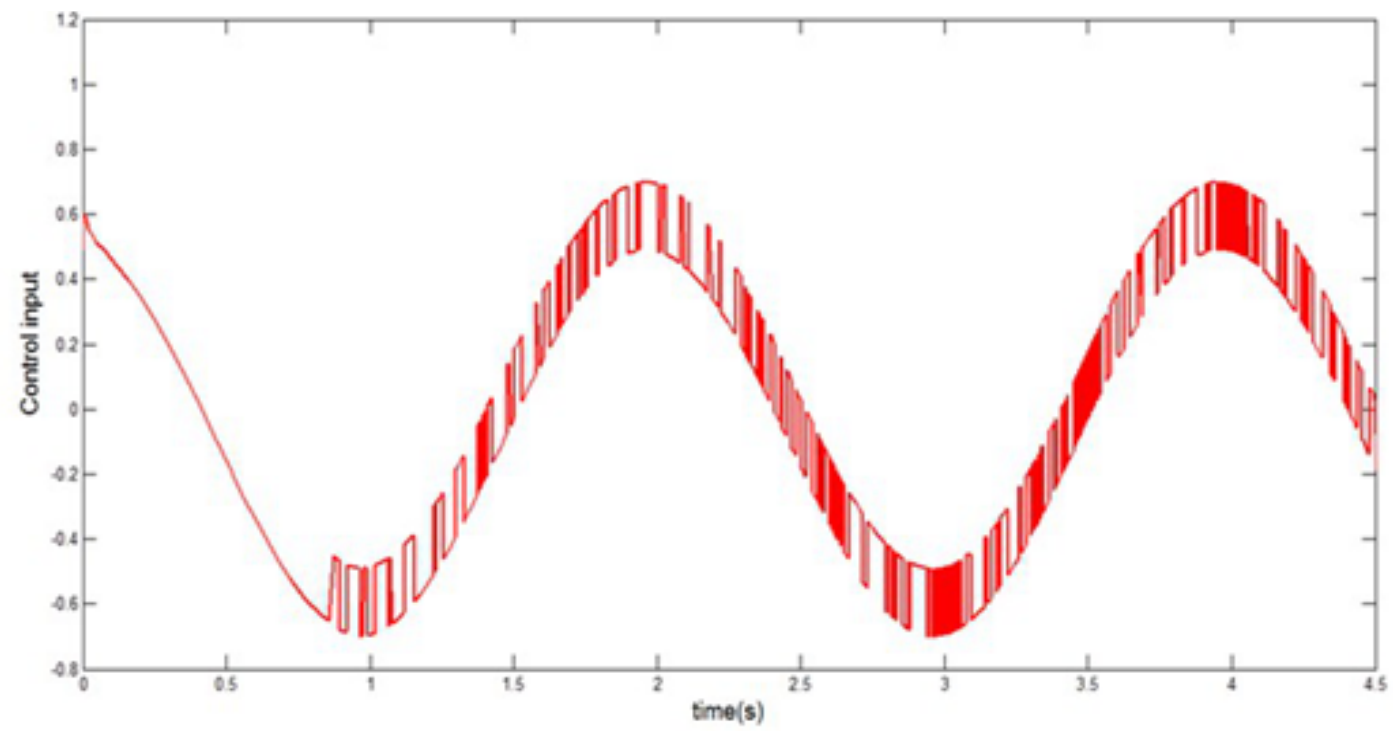

Fig. (7). Control input with SMC.

$$
\begin{aligned}
& \frac{\partial s(t) \dot{s}(t)}{\partial u}=s(t) \frac{\dot{s}(t)}{\partial u}=-b s(t) \\
& \frac{\partial u(t)}{\partial w_{j}(t)}=\exp \left(-\frac{\left\|s-c_{j}\right\|^{2}}{b_{j}}\right)
\end{aligned}
$$

The learning algorithm of network weights is given as:

$$
d w_{j}=\psi(t) \exp \left(-\frac{\left\|s-c_{j}\right\|^{2}}{b_{j}}\right)=\psi(t) h_{j}(s)
$$

The structure of sliding mode controller with RBF neural sliding mode controller is shown in Fig. (6),

\section{NUMERICAL SIMULATION}

In this paper the MATLAB is used to make simulation for the hydraulic servo system to confirm the effectiveness of the controller. Through looking up the corresponding parameters of hydraulic servo system for the parallel machine tool, the transfer function of system is given as following.

$$
G(s)=\frac{13341}{s\left(s^{2}+56.2 s+6542\right)}
$$

Based on the RBF neural sliding mode control, the input of RBF network is given as $\left[x_{1}, x_{2}, x_{3}\right]$.

The initial value of weights $w$ is $[0.1,0.1,0.1]^{T}$, disturbance and uncertain item are selected as $0.5 \sin (2 \pi t)$, 


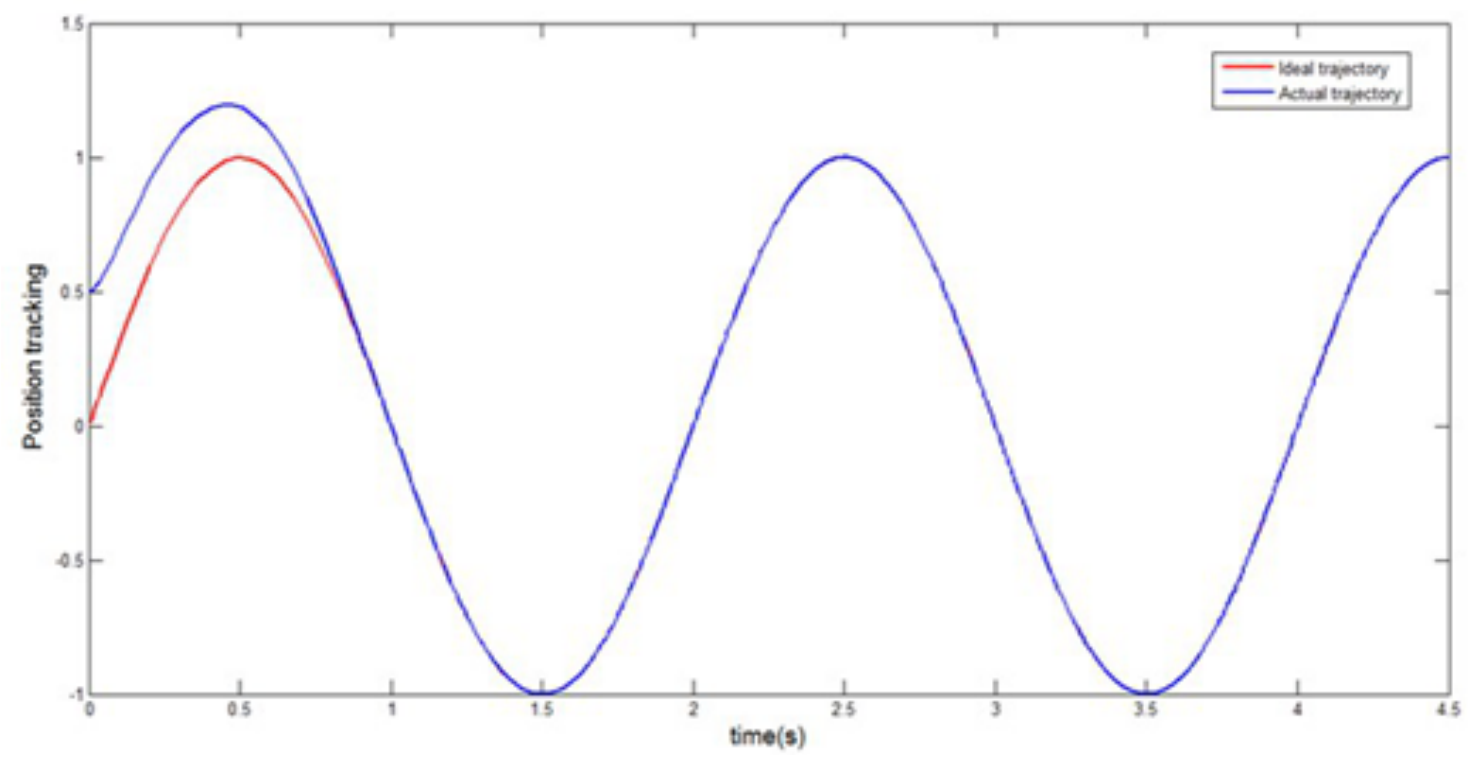

Fig. (8). Position tracking with SMC.

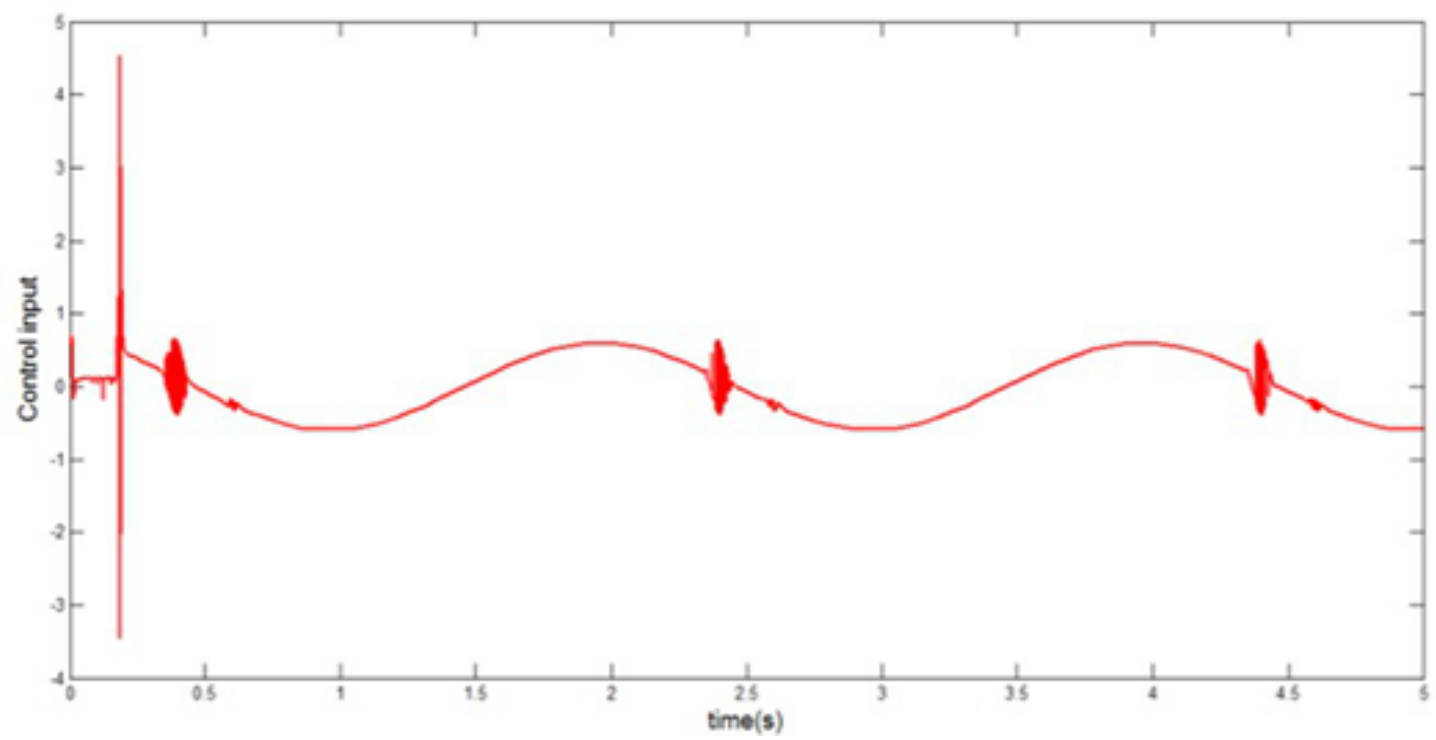

Fig. (9). Control input with SMC Based RBF.

$k_{1}=100, k_{2}=200, c=30$ the position index is $\sin (\pi t)$. The control input and position tracking of system with SMC is given in Fig. (7 and 8). The control input and position tracking of system with SMC based on RBF neural network is given in Fig. (9 and 10).

\section{CURRENT \& FUTURE DEVELOPMENTS}

Sliding mode control is made robust with respect to system uncertainties through the use of switching control, but it has disadvantage of chattering. In order to reduce the chattering of servo system, the sliding mode control method based on RBF neural network is proposed in this paper. By analyzing the previous control strategy, we propose the sliding mode control strategy based on RBF neural network, which makes SMC optimized by the BRF neural network. From the simulation results we obtained the performance of the proposed controller has some effectiveness. Moreover, the proposed method validates the Hydraulic system of parallel machine tool and also provides its theoretical and experimental basis.

According to the current development condition, the main developmental directions of the sliding mode control system are stated below.

1. Adjusting the term gain switching Online is an effective method to eliminate chattering. We can realize the 


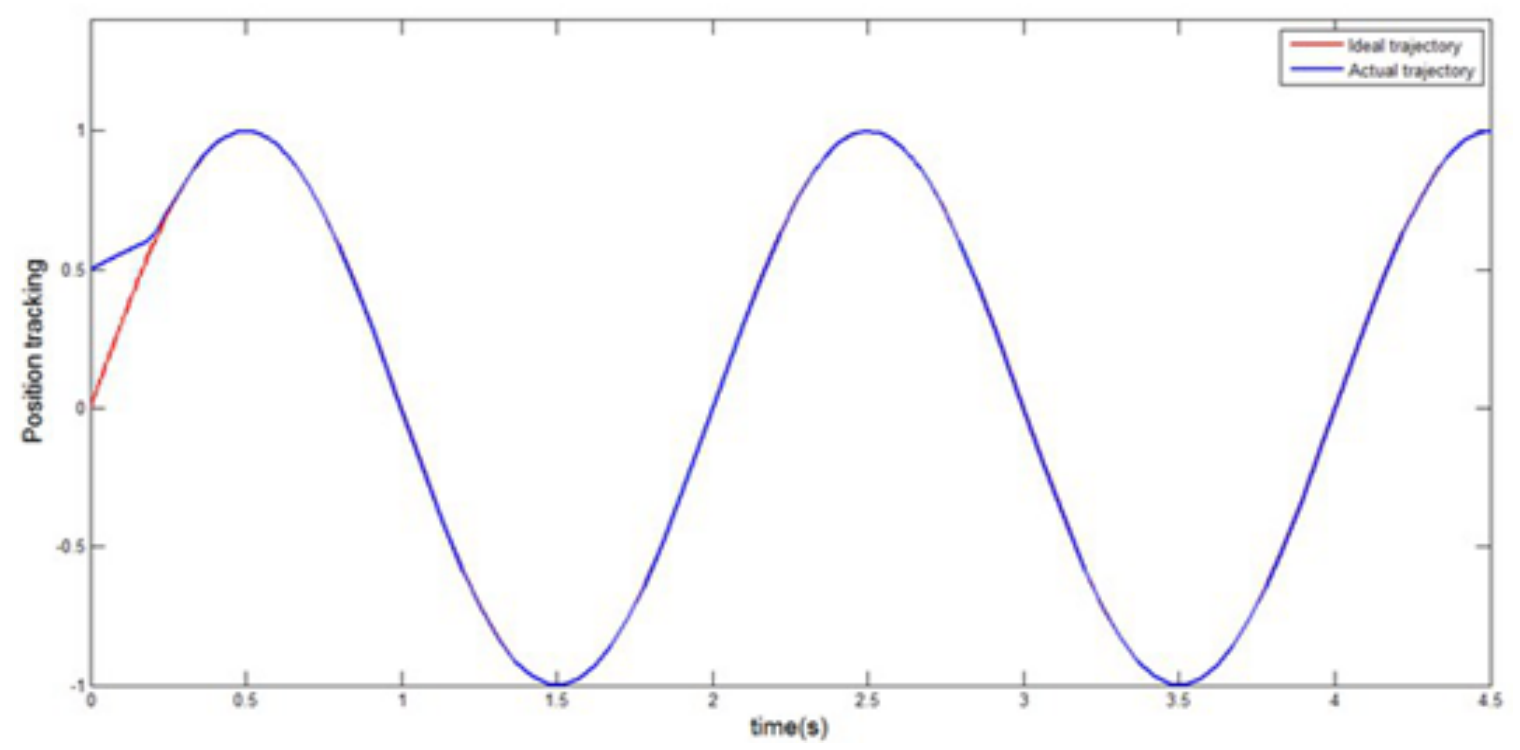

Fig. (10). Position tracking with SMC Based RBF.

switch gain of online optimization, thus minimizing the term gain switching by use of advanced intelligent methods (fuzzy algorithm [18, 19], neural network and genetic algorithm $[20,21]$, etc.) of sliding mode control.

2. The theory of terminal sliding mode control needs further development. The terminal sliding mode control method mainly refers to convergence to zero in finite time, how to implement the system state convergence to zero within the limited space is the direction of further development of this method.

3. At present, the new sliding mode control method (such as a Terminal sliding mode control, the inversion of sliding mode control and dynamic sliding mode control, etc.) are mostly in the stage of theoretical research.

4. The new sliding mode control method which is applied to actual engineering system in solving practical engineering problems is the focus of future research. Sliding mode control of high order system which has been proposed recently is one of the promising method; there are many problems that need to be researched. If it can be combined with some new method of sliding mode control in the future, we will be able to get better performance of the new type of sliding mode controller.

\section{CONFLICT OF INTEREST}

The authors confirm that this article content has no conflict of interest.

\section{ACKNOWLEDGEMENTS}

This work is supported by the Research Foundation of mathematics teaching team of Chaohu Universi$\operatorname{ty}(\mathrm{Ch} 12 \mathrm{td} 01)$.

\section{REFERENCES}

[1] D. A. Stewart, "Platform with 6 -DOF". Proceedings on Institution of Mechanical Engineering, vol. 18, pp. 371-386, Jan. 1965.

[2] H. Wang, L. Wei, and R. Wang, "The study of the theory of the parallel robot," Automation Panorama, vol. 19, pp. 42-45, May 2002.

[3] Z. S. Wu, Hydraulic control system: Higher Education Press, Beijing, 2008.

[4] H. Yang, K. Zhao, and S. Wu, "Control strategy of a hydraulic 6dof parallel robot," Robot, vol. 26, pp. 263-266, 2004.

[5] R. Huang, and Y. Gao, "A kind of parallel robot robust optimal control structure," Journal of Yanshan University, vol. 23, pp. 175$177,1999$.

[6] Y. Li, Y. Wang, Z. Chen, and R. Zhao, "The state of research on intelligent control of parallel robot," Machine Tool \& Hydraulics, vol. 36, pp. 112-120, Dec. 2008

[7] Yuji Yasui, S. Akazaki, and K. Hanada, "Sliding mode control method," E. P. Patent 0800125, Oct. 8, 1997.

[8] H. Nishida, S. Ken, and Hideyuki, "Sliding mode control apparatus and adjusting method," W. O. Patent PCT/JP2006/319402, Mar. 29, 2007.

[9] B.B. Glenn, J.H. Saunders, A.B. Kenoe, I.F. Whitney, R.T. Berger, and C. Bradley, "Mass flow controller employing sliding mode control," W. O. Patent PCT/US2008/056005, Sep. 11, 2009.

[10] J. Zhang, G. Wen, Y. Wei, and G. Yin, "RBF Neural Network PID for Bilateral Servo Control System," Telkomnika, vol. 11, pp. 52005209, 2013.

[11] J.K.L. MATLAB Simulation for Sliding Mode Control: Tsinghua University Press, Beijing, 2004.

[12] W.P. Hobson, P. Hamer, K.J. Twitchen, P.C. Barson, S. Field, and T. J. Edwards, "Monitoring and Retraining Neuralnetwork," C. A. Patent 2249316, July 23, 1998.

[13] A. Nogaret, "Neural Network," W. O. Patent PCT/GB2013/051178, Nov. 8, 2013.

[14] H. Wang, Q. Li, and W. Song, "Study of a sort of flexible structure fuzzy logic controller applied on position control system of parallel robot," Journal of Yanshan University, vol. 22, pp. 79-87, Jan. 1998.

[15] Z. M. Chen, J. G. Zhang, Z. Y. Wang, and J. C. Zeng, "Sliding mode control of manipulator based on neural network reaching law," IEEE International Conference on Control and Automation, 2008, pp. 370-373.

[16] J. H. Horng, "Neural adaptive tracking control of a DC motor," Information Sciences, vol. 118, pp. 1-13, Sep. 1999. 
[17] L. H. Hassan, M. Moghavvemi, A. F. A. Haider, and O. Steinmayer, "Current state of neural networks applications in power system monitoring and control," Electrical Power and Energy Systems, vol. 51, pp. 134-144, May 2013.

[18] L. Cho, "Apparatus and method for estimating state of charge in battery using fuzzy algorithm implemented as neural network," U. S. Patent 12869242, Dec. 23, 2010.
[19] J. A. Stanley, "Elevator car dispatching including passenger destination information and a fuzzy logic algorithm," U. S. Patent 11214089, Jan. 3, 2007.

[20] A. Miyanaga, "Microprocessor using genetic algorithm," U. S. Patent 10878011, June 1, 2005.

[21] S. Lineaweaver, "Using a genetic algorithm employing dynamic mutation," U. S. Patent 12557218, Mar. 10, 2011.

Received: October 29, 2014

(C) Yang et al.; Licensee Bentham Open.

This is an open access article licensed under the terms of the Creative Commons Attribution Non-Commercial License (http://creativecommons.org/licenses/by-nc/3.0/) which permits unrestricted, non-commercial use, distribution and reproduction in any medium, provided the work is properly cited. 